\title{
NECESSARY AND SUFFICIENT CONDITIONS FOR THE ERGODICITY OF MARKOV CHAINS WITH TRANSITION $\Delta_{m, n}\left(\Delta_{m, n}^{\prime}\right)$-MATRIX
}

\author{
L. ABOLNIKOV \\ Loyola Marymount University \\ Los Angeles, California \\ and \\ A. DUKHOVNY \\ Scientific Research Institute on Automation \\ Odessa, U.S.S.R.
}

\begin{abstract}
This paper isolates and studies a class of Markov chains with a special quasi-triangular form of the transition matrix [so-called $\Delta_{\mathrm{m}, \mathrm{n}}$ $\left(\Delta_{m, n}^{\prime}\right)$-matrix]. Many discrete stochastic processes encountered in applications (queues, inventories and dams) have transition matrices which are special cases of a $\Delta_{m, n}\left(\Delta_{m, n}^{\prime}\right)$-matrix. Necessary and sufficient conditions for the ergodicity of a Markov chain with transition $\Delta_{\mathrm{m}, \mathrm{n}}\left(\Delta_{\mathrm{m}, \mathrm{n}}^{\prime}\right)$-matrix are determined in the article in two equivalent versions. According to the first version, these conditions are expressed in terms of certain restrictions imposed on the generating functions $A_{i}(x)$ of the elements of the $i$-th row of the transition matrix, $i=0,1,2, \ldots ;$ in the other version they are connected with the characterization of the roots of a certain associated function in the unit circle of the complex plane. Results obtained in the article generalize, complement, and refine similar results existing in the literature.
\end{abstract}

Key words: Markov chains, queues, inventories, dams, ergodicity, necessary condition, sufficient condition

AMS subject classification: 60J, 60K25

\section{INTRODUCTION}

A class of Markov stochastic processes with transition (or infinitesimal) matrix of the form 


$$
\mathrm{G}=\left[\begin{array}{cccc}
\mathrm{g}_{0,0} & \mathrm{~g}_{0,1} & \mathrm{~g}_{0,2} & \ldots \\
\mathrm{g}_{1,0} & \mathrm{a}_{1,1} & \mathrm{a}_{1,2} & \ldots \\
\mathrm{g}_{2,0} & \mathrm{~g}_{2,1} & \mathrm{~g}_{2,2} & \ldots \\
\ldots & \ldots & \ldots & \ldots \\
\mathrm{g}_{\mathrm{m}, 0} & \mathrm{~g}_{\mathrm{m}, 1} & \mathrm{~g}_{\mathrm{m}, 2} & \ldots \\
0 & \mathrm{~g}_{\mathrm{m}+1,1} & \mathrm{~g}_{\mathrm{m}+1,2} & \ldots \\
0 & 0 & \mathrm{~g}_{\mathrm{m}+2,2} & \ldots \\
\ldots & \ldots & \ldots & \ldots
\end{array}\right]
$$

(a " $\Delta_{\mathrm{m}}$-matrix") or of the form $\mathrm{G}^{\prime}\left(\mathrm{a} \Delta_{\mathrm{m}}^{\prime}\right.$-matrix*) was first investigated for the case of finite set of states by Abolnikov in [1]. A method was proposed for reducing the problem of finding the state probabilities for such a process to the simpler problem of finding the state probabilities for an auxiliary process whose transition matrix is related to the $\Delta_{\mathrm{m}}$ $\left(\Delta_{\mathrm{m}}^{\prime}\right)$-matrix of the original process. (This was called, "the continuation method"). In particular, this method provides the solution for the finite dimensional case if a solution is available for the infinite-dimensional case. Markov chains with an infinite transition matrix which is a slightly modified analog of (1.1) was investigated by Neuts [11]. In this paper a new effective approach for finding the steady-state probabilities of the process was proposed.

However, the questions related to the conditions for the ergodicity of such processes were not considered in $[1,11]$. The present paper is devoted to this problem. As the main object of consideration we study a countable Markov chain whose transition matrix has form (1.1). Keeping in mind the specific features of processes which are frequently encountered in application, we do not impose any restrictions on the transient probabilities $g_{i j}$ if $i \leq m(j \leq n)$, but suppose at the same time that the $g_{i j}$ for $i>n(j>n)$ depend only on the difference of the indices $i$ and $j$. That is, the transition matrix of processes considered in the paper has the following form:

${ }^{*} G^{\prime}$ is the transpose of $G$. 


$$
A=\left[\begin{array}{ccccccc}
a_{00} & a_{10} & \ldots & a_{0 n-m} & a_{0 n-m+1} & a_{0 n-m+2} & \cdots \\
a_{10} & a_{11} & \ldots & a_{1 n-m} & a_{1 n-m+2} & a_{1 n-m+2} & \cdots \\
\cdots & \cdots & \cdots & \cdots & \cdots & \cdots & \cdots \\
a_{n 0} & a_{n 1} & \ldots & a_{n n-m} & a_{n n-m+1} & a_{n n-m+2} & \cdots \\
0 & 0 & \ldots & 0 & k_{0} & k_{1} & \cdots \\
0 & 0 & \ldots & 0 & 0 & k_{0} & \cdots \\
\cdots & \ldots & \ldots & \ldots & \ldots & \cdots & \cdots
\end{array}\right]
$$

or its transpose. Many stochastic processes encountered in applications have transition matrices which are special cases of $\mathrm{A}$ (or $\mathrm{A}^{\prime}$ ). As examples there are embedded Markov chains describing the behavior of a queue in the queueing systems M/G/1, G/M/1, G/M/n with bulk arrivals, bulk service, with feedback, with a threshold, with "warmup", with switchings, with hysteresis service, and with queue buildup; the state of a storage in the theory of inventory control; the state of a dam in the Moran problem. In this paper necessary and sufficient conditions for the existence of the ergodic distribution of the probabilities of states of a Markov chain with infinite transition $\Delta_{\mathrm{m}, \mathrm{n}}\left(\Delta_{\mathrm{m}, \mathrm{n}}^{\prime}-\right.$ matrix $)$ are determined. These conditions then are connected with the existence and the location of the roots of the function

$$
\mathrm{z}^{\mathrm{m}}-\mathrm{k}^{\prime}(\mathrm{z}), \quad \mathrm{k}(\mathrm{z})=\sum_{\mathrm{i}=0}^{\infty} \mathrm{k}_{\mathrm{i}} \mathrm{z}^{\mathrm{i}} .
$$

Some special cases (as a rule, connected with queueing systems) of this problem yielding mostly sufficient conditions were discussed in Abolnikov/Dshalalow [2], Abolnikov [3], Bahary/Kolesar [4], Bailey [5], Delbrouck [6], Harris/Marlin [7], Kopocinska [8], and Loris-Teghem [9].

However, the arguments given suffer either from insufficient analytical justification or from considerable restriction of the generality. The same can be said about the characterization of the roots of the function $\mathrm{z}^{\mathrm{m}}-\mathrm{k}(\mathrm{z})$ in the circle $|\mathrm{z}| \leq 1$. In Bahary/Kolesar [4] the question of determination of the roots of $z^{m}-k(z)$ is left open. In Harris/Marlin [7] the proof of the statement about the number of the roots of the function $\mathrm{z}^{\mathrm{m}}-\mathrm{k}(\mathrm{z})$ is given only under the suggestion of the possibility of the analytical extension of the $\mathrm{k}(\mathrm{z})$ outside of the unit circle. The solution of the problem was obtained in Abolnikov/Dshalalow [2] and Abolnikov [3] only for the sufficient conditions and $\mathrm{m}=1$.

\section{DEFINITIONS AND TERMINOLOGY}

Definition 1. We shall say that a finite (not necessarily square) or an infinite stochastic matrix $A=\left(a_{i j}\right)$ is a $\Delta_{m, n}$-matrix (resp. $\Delta_{m, n}^{\prime}$-matrix), $n \geq m \geq 1$, if $a_{i j}=0$ for $\mathrm{i}>\mathrm{n}$ and $\mathrm{i}$ $-j>m$ (resp. $a_{i j}=0$ for $j>m$ and $j-i>m$ ). If in addition $a_{i j}=k_{j-i+m}$ for $i>n, j>m$ (resp. $a_{i j}=k_{i-j+m}$ for $j>n, i>j-m$ ) then the matrix $A$ is called homogeneous. 
Another definition of a homogeneous $\Delta_{\mathrm{m}, \mathrm{n}}$-matrix (that is more convenient in the case of infinite matrices) can be given in the following way. Let

$$
A_{i}(z)=\sum_{j=0}^{\infty} a_{i j} z^{j}
$$

be a generating function of elements $a_{i j}$ of the $i$-th row of a stochastic matrix $A=\left(a_{i j}\right)$, $i=0,1,2, \ldots$. The set of functions $A_{i}(z), i=0,1,2, \ldots$, obviously, completely determines the matrix $\mathrm{A}$.

Definition 2. An infinite stochastic matrix $A=\left(a_{i j}\right), i, j=0,1,2, \ldots$ is called a homogenous $\Delta_{\mathrm{m}, \mathrm{n}}$-matrix if

$$
A_{i}(z)=z^{i-m} \sum_{r=0}^{\infty} k_{r} z^{r}, i=n+1, n+2, \ldots .
$$

Let $\xi_{\mathrm{r}}, \mathrm{r}=0,1,2 \ldots$, be a homogeneous Markov chains with transition $\Delta_{\mathrm{m}, \mathrm{n}^{-}}$ matrix $A=\left(a_{i j}\right), i, j=0,1,2, \ldots$. We denote

$$
\begin{aligned}
& p_{i}^{(r)}=P\left\{\xi_{r}=i\right\} ; \pi_{i}=p_{i}^{(0)}, i=0,1,2, \ldots ; \\
& p^{(r)}=\left(p_{0}^{(r)}, p_{1}^{(r)}, p_{2}^{(r)}, \ldots\right), r=0,1,2, \ldots ; \pi(z)=\sum_{i=0}^{\infty} \pi_{i} z^{i} ; \\
& u_{i}(x)=\sum p_{i}^{(r)} x^{r} ; w(x, z)=\sum_{i=0}^{\infty} u_{i}(x) z^{i} ;|x|<1,|z| \leq 1 ; \\
& u(x)=\left(u_{0}(x), u_{1}(x), u_{2}(x), \ldots\right)=\sum_{r=0}^{\infty} p^{(r)} x^{r} ; \\
& \lim _{r \rightarrow \infty} p_{i}^{(r)}=p_{i}, P=\left(p_{0}, p_{1}, p_{2}, \ldots\right) ; P(z)=\sum_{i=0}^{\infty} p_{i} z^{i} .
\end{aligned}
$$

Let us point out some useful relationships among the vectors

$\mathbf{P}, \mathbf{p}^{(\mathrm{r})}, \mathbf{u}(\mathrm{x})$ and the matrix $\mathrm{A}$, which will be used later.

First, since the chain $\xi_{\mathrm{r}}$ is homogeneous

If the chain $\xi_{\mathrm{r}}$ is ergodic then and, finally, it is easy to see that

$$
p^{r+1}=p^{r} A
$$

$$
\mathbf{P}=\mathbf{P} \mathbf{A},
$$

$$
\mathbf{u}(\mathbf{x})=\mathbf{x u}(\mathbf{x}) \mathrm{A}+\mathbf{p}^{0} \text {. }
$$


The problem consists in finding necessary and sufficient conditions for the ergodicity of the chain $\xi_{\mathrm{r}}$.

\section{NECESSARY AND SUFFICIENT CONDITIONS FOR THE ERGODICITY OF MARKOV CHAINS WITH TRANSITION $\Delta_{\mathrm{m}, \mathrm{n}}$ and $\Delta_{\mathrm{m}, \mathrm{n}}^{\prime}$-MATRICES.}

Theorem 1. A Markov chain $\xi_{\mathrm{r}}$ with transition irreducible and nonperiodic homogeneous $\Delta_{m, n}$-matrix $A=\left(a_{i j}\right), i, j=0,1,2, \ldots$ is ergodic if and only if

$$
A_{i}^{\prime}(1)<\infty, i=0,1,2, \ldots, n
$$

and

Proof:

$$
\mathrm{k}^{\prime}(1)<\mathrm{m} \text {. }
$$

Sufficiency. Let us put $\mathrm{x}_{\mathrm{j}}=\mathrm{j}, \mathrm{j}=0,1,2, \ldots$; then it follows from (1.2) that

$$
\sum_{j=0}^{\infty} a_{i j} x_{j}-x_{i}=\left\{\begin{array}{l}
A_{i}^{\prime}(1)-i, \text { if } i=0,1, \ldots, n \\
k^{\prime}(1)-m, \text { if } i=n+1, n+2, \ldots
\end{array}\right.
$$

By the corollary of Moustafa [10] to Foster's theorem we conclude that (3.1) and (3.2) are sufficient for the ergodicity of the chain $\xi_{\text {r }}$.

Necessity. Let us first prove the following lemma.

Lemma . Consider a function

$$
\mathrm{H}(\mathrm{z})=\sum_{\mathrm{i}=0}^{\infty} \mathrm{h}_{\mathrm{i}} \mathrm{z}^{\mathrm{i}},
$$

which converges for $z=1$. Suppose that $h_{i} \leq 0$ if $i=0,1,2, \ldots, k$, and $h_{i} \geq 0$ if $i=k+1$, $\mathrm{k}+2, \ldots$.

Assume further that $H \neq 0$. If there exists $z_{0} \in(0,1)$, such that $H\left(z_{0}\right) \geq 0$, the $H(z) \geq 0$ for any $\mathrm{z} \in\left(\mathrm{z}_{0}, 1\right]$.

Proof. Under the conditions of the lemma the following chain of inequalities for any $\mathrm{z} \in\left(\mathrm{z}_{0}, 1\right]$ is valid:

$$
-z^{-(k+1)} \sum_{i=0}^{k} h_{i} z^{i} \leq-z_{0}^{-(k+1)} \sum_{i=0}^{k} h_{i} z_{0}^{i} \leq-z_{0}^{-(k+1)} \sum_{i=k+1}^{\infty} h_{i} z_{0}^{i} \leq z^{-(k+1)} \sum_{i=k+1}^{\infty} h_{i} z^{i}
$$

Since $H(z) \neq 0$, at least one of the $h_{i}, i=0,1,2, \ldots$ is not equal to 0 . Therefore, at least one of the extreme inequalities in the chain is strict. The lemma then follows.

We now return to the proof of the theorem. If the chain $\xi_{\mathrm{r}}$ is ergodic, then there exists a strictly positive vector $\mathbf{P}=\left(\mathrm{p}_{0}, \mathrm{p}_{1}, \mathrm{p}_{2}, \ldots\right)$ such that $\mathbf{P}=\mathbf{P A}$.

Multiplying this equation by the vector $\left(0,0,0, \ldots \mathrm{z}^{\mathrm{m}}, \mathrm{z}^{\mathrm{m}+1}, \ldots\right)$ with 0 's in the first $\mathrm{n}+1$ places, where $\mathrm{z} \in[0,1]$ and taking into account $(1.1)$ we obtain 


$$
\begin{aligned}
& \sum_{i=0}^{\infty} p_{n+i+1} z^{i}=\frac{H(z)}{z^{m}-k(z)} \text {, where } \\
& H(z)=\sum_{i=0}^{\infty} h_{i} z^{i}=z^{m} \sum_{i=0}^{n} p_{i} \sum_{j=0}^{\infty} a_{1}{ }_{n+j+1} z^{j}-\sum_{i=0}^{m-1} p_{n+i+1} \sum_{j=0}^{m-i-1} h_{j} z^{j} .
\end{aligned}
$$

It is easy to see that

$$
0<\lim _{\mathrm{z} \rightarrow 1-} \frac{\mathrm{H}(\mathrm{z})}{\mathrm{z}^{\mathrm{m}}-\mathrm{k}(\mathrm{z})}=\sum_{\mathrm{i}=0}^{\infty} \mathrm{p}_{\mathrm{n}+\mathrm{i}+1}<1,
$$

and since $\left.\left[\mathrm{z}^{\mathrm{m}}-\mathrm{k}(\mathrm{z})\right]\right|_{\mathrm{z}=1}=0$ then

$$
h(1)=\lim _{z \rightarrow 1-} H(z)=0 .
$$

It follows that $\mathrm{H}(\mathrm{z})<0$ for any $\mathrm{z} \in(0,1)$. Indeed, suppose that there exists $\mathrm{z}_{0} \in(0,1)$ such that $\mathrm{H}\left(\mathrm{z}_{0}\right) \geq 0$. Then, since

$$
\mathrm{H}(0)=\mathrm{h}_{0}=-\mathrm{k}_{0} \sum_{\mathrm{i}-0}^{\mathrm{m}-1} \mathrm{p}_{\mathrm{n}+\mathrm{i}+1}<0
$$

the Lemma implies $\mathrm{h}(1)>0$, which contradicts (3.4).

We shall need an additional property of $\mathrm{H}(\mathrm{z})$, namely

$$
0<\mathrm{H}^{\prime}(1)<\infty .
$$

To prove this let us notice that $\mathrm{k}^{\prime}(1) \leq \mathrm{m}$, because otherwise there exists $\delta>0$ such that $\mathrm{z}^{\mathrm{m}}-\mathrm{k}(\mathrm{z})>0$ for any $\mathrm{z} \in(1-\delta, 1)$. Therefore,

$$
\frac{\mathrm{H}(\mathrm{z})}{\mathrm{z}^{\mathrm{m}}-\mathrm{k}(\mathrm{z})}<0 \text { in the same region, which is impossible because of (3.3). }
$$

Now to prove the right inequality in (3.5) it is enough to pass to the limits in (3.3) as $z \rightarrow$ 1-. Let us first consider the left inequality in (3.5) for $m=1$. It is obvious that $i h_{i} \geq 0$ for any $\mathrm{i}=0,1,2, \ldots$. On the other hand, since the chain $\xi_{\mathrm{r}}$ is irreducible, among the numbers $a_{i n+j+1}, i=0,1,2, \ldots, h, j=0,1,2, \ldots$ so there exists at least one which is strictly positive. It follows that there exists $i_{0}$, such that

$$
\mathrm{i}_{0} \mathrm{~h}_{\mathrm{i}_{0}}>0 \text { and, therefore, } \mathrm{H}^{\prime}(\mathrm{l}) \geq \mathrm{i}_{0} \mathrm{~h}_{\mathrm{i}_{0}}>0 \text {. }
$$

If $m>1$ then

$$
\mathrm{H}^{\prime}(0)=\mathrm{h}_{1}=-\mathrm{k}_{1} \sum_{\mathrm{i}=0}^{\mathrm{m}-2} \mathrm{p}_{\mathrm{n}+\mathrm{i}+1}<0 .
$$

In addition, since $\mathrm{H}(0)<0$ and $\mathrm{H}(1)=0$, there exists $\mathrm{z}_{0} \in(0,1)$ such that $\mathrm{H}^{\prime}\left(\mathrm{z}_{0}\right)>0$. By the lemma it follows that $\mathrm{H}^{\prime}(1)>0$ and (3.5) is proved. 
Now both of the statements (3.1) and (3.2) of the theorem 1 easily follow from (3.3) and (3.5). In fact, if we suppose that there exists $i$, such that $A_{i}{ }^{\prime}(1)=\infty$ then, as can be seen from the form of $\mathrm{H}(\mathrm{z}), \lim \mathrm{H}^{\prime}(\mathrm{z})=\infty$, which contradicts (3.5). Finally, the statement (3.2) of the theorem can be obtained by passing to the limits in (3.3) as $\mathrm{z} \rightarrow 1$ and taking into account (3.5). The theorem is proven.

Next we establish an analogous statement for a Markov chain $\xi_{\mathrm{r}}, \mathrm{r}=0,1,2, \ldots$ with transition matrix of $\Delta_{\mathrm{m}, \mathrm{n}}^{\prime}$-type.

Theorem 2: A Markov chain $\xi_{\mathrm{r}}, \mathrm{r}=0,1,2, \ldots$ with transition irreducible aperiodic homogeneous $\Delta_{m, n}^{\prime}$-matrix $A=\left(a_{i j}\right), i, j=0,1,2, \ldots$ is ergodic if and only if

$$
\mathrm{k}^{\prime}(1)>\mathrm{m}
$$

Proof:

Sufficiency.

Let us put $x_{i}=\max \{j-n, 0\}=0, \infty$. Then taking into account (1.2) it is easy to show that

$$
\sum_{j=0}^{\infty} a_{i j} x_{j}-x_{i}=\left\{\begin{array}{cl}
0 & , \text { if } i<n-m \\
D_{z}^{i-n+m} \frac{k(z)-z^{m}}{(1-z)^{2}}, & \text { if } i \geq n-m
\end{array}\right.
$$

where $D_{x}^{i}$ is an operator defined by the relation

$$
\begin{aligned}
& D_{x}^{i} F(x, y)=\left.\frac{1}{i !} \frac{\partial^{i} F(x, y)}{\partial x^{i}}\right|_{x=0} \\
& \text { Note that } D_{z}^{i} \frac{K(z)-z^{m}}{1-z}=\left\{\begin{array}{l}
\sum_{j=0}^{i} k_{j} \geq 0, \quad \text { if } i<m \\
\sum_{j=0}^{i} k_{j}-1 \leq 0, \text { if } i \geq m
\end{array}\right.
\end{aligned}
$$

and, therefore, if $\mathrm{i}<\mathrm{m}$,

$$
D_{z}^{i} \frac{k(z)-z^{m}}{(1-z)^{2}}=\sum_{j=0}^{i} D_{z}^{j} \frac{k(z)-z^{m}}{1-z} \geq 0
$$

and if $\mathrm{i} \geq \mathrm{m}-1$

$$
D_{z}^{i+1} \frac{k(z)-z^{m}}{(1-z)^{2}} \leq D_{z}^{i} \frac{k(z)-z^{m}}{(1-z)^{2}}
$$

Hence, the sequence 


$$
\left\{D_{z}^{i} \frac{k(z)-z^{m}}{(1-z)^{2}}\right\}_{i=1}^{\infty}
$$

either has a finite limit as $\mathrm{i} \rightarrow \infty$, or tends to $+\infty$. If $\mathrm{k}^{\prime}(1)>\mathrm{m}$ then using a Tauberian theorem in the case of the finite limit we obtain:

$$
\lim _{i \rightarrow \infty} D_{z}^{i} \frac{k(z)-z^{m}}{(1-z)^{2}}=\lim _{z \rightarrow 1-0} \frac{k(z)-z^{m}}{1-z}=-k^{\prime}(1)+m<0
$$

so that in this case there exist $\mathrm{s}$ and $\mathrm{M}<0$ such that

$$
\sum_{j=0}^{\infty} a_{i j} x_{j}-x_{i}<M, \text { if } i>s .
$$

Again appealing to the criterion of Moustafa [10] we conclude that (3.6) is sufficient for the ergodicity of the chain $\xi_{\mathrm{r}}$.

Necessity. If the chain $\xi_{\mathrm{r}}$ is ergodic then there exists a strictly positive probability vector $\mathbf{P}$ $=\left(\mathrm{p}_{0}, \mathrm{p}_{1}, \mathrm{p}_{2}, \ldots\right)$ such that $\mathrm{P}=\mathrm{PA}$. Multiplying this equation by the vector $\left(\mathrm{x}_{0}, \mathrm{x}_{1}, \mathrm{x}_{2}\right.$, $\ldots$ ), where $x_{j}=\max \{j-n, 0\}, j=0,1,2, \ldots$, after some simple transformations, we obtain

$$
\sum_{i=0}^{\infty} p_{n+1-m+1} D_{z}^{i} \frac{k(z)-z^{m}}{(1-z)^{2}}=0 .
$$

Suppose that $\mathrm{k}^{\prime}(1) \leq \mathrm{m}$. Then

$$
\lim _{i \rightarrow \infty} D_{z}^{i} \frac{k(z)-z^{m}}{(1-z)^{2}}=\lim _{i \rightarrow \infty} \sum_{j=0}^{i} D_{z}^{j} \frac{k(z)-z^{m}}{1-z}=-k(1)+m \geq 0 .
$$

Together with (3.8) and (3.9), this implies that

$$
\mathrm{D}_{\mathrm{z}}^{\mathrm{i}} \frac{\mathrm{k}(\mathrm{z})-\mathrm{z}^{\mathrm{m}}}{(1-\mathrm{z})^{2}} \geq 0
$$

for all $\mathrm{i}=0,1,2, \ldots$, which contradicts (3.10). The theorem is proved.

\section{ERGODICITY OF THE MARKOV CHAIN WITH TRANSITION $\Delta_{\mathrm{m}, \mathrm{n}}\left(\Delta_{\mathrm{m}, \mathrm{n}}^{\prime}\right)-$ MATRIX \\ AND CHARACTERIZATION OF THE ROOTS OF THE FUNCTION $\mathrm{z}^{\mathrm{m}}$ - $\mathrm{k}(\mathrm{z})$.}

The conditions of ergodicity proved in section 3 are closely connected with the number and location of the roots of the function $\mathrm{z}^{\mathrm{m}}-\mathrm{k}(\mathrm{z})$. More precisely, the following theorem is valid.

Theorem 3 
A. If $\mathrm{k}^{\prime}(1)<\mathrm{m}$, then the function $\mathrm{z}^{\mathrm{m}}-\mathrm{k}(\mathrm{z})$ has exactly $\mathrm{m}$ roots (counting multiplicities) in the disc $|z| \leq 1$. The roots lying on the boundary are simple and, for some integer $r$, they are all $r$-th roots of 1 .

B. If $\mathrm{k}^{\prime}(1)>\mathrm{m}$, then the function $\mathrm{z}^{\mathrm{m}}-\mathrm{k}(\mathrm{z})$ has exactly $\mathrm{m}$ roots (counting multiplicities) in the open disc $|z|<1$; on the boundary there can be $r$ additional simple roots which are all the $r$-th roots of 1 , where $r$ is an integer, $1 \leq \mathrm{r} \leq \mathrm{m}$.

Proof: We will need the following result.

Lemma. The function $\mathrm{z}^{\mathrm{m}}-\mathrm{k}(\mathrm{z})$ has roots on the unit circle $|\mathrm{z}|=1$ if and only if there exists $r$ such that $m \mid r$ and for any $i$ such that $k_{i} \neq 0, i \mid r$. If these conditions are satisfied, then all roots of this kind coincide with the roots of the equation $\mathrm{z}^{r}-1=0$, where $\mathrm{r}$ is the maximal number having this property.

Proof: Suppose that $\mathrm{z}_{0}$ is a root of the equation $\mathrm{z}^{\mathrm{m}}-\mathrm{k}(\mathrm{z})=0$ such that $\left|\mathrm{z}_{0}\right|=1$. Then

$$
\left|\mathrm{k}\left(\mathrm{z}_{0}\right)\right|=\left|\mathrm{z}_{0}^{\mathrm{m}}\right|=1 \text {. }
$$

On the other hand,

$$
\left|\mathrm{k}\left(\mathrm{z}_{0}\right)\right|=\left|\sum_{\mathrm{i}=0}^{\infty} \mathrm{k}_{\mathrm{i}} \mathrm{z}_{0}\right| \leq \sum_{\mathrm{i}=0}^{\infty} \mathrm{k}_{\mathrm{i}}\left|\mathrm{z}_{0}\right|^{\mathrm{i}}=1
$$

and the equality is attained if and only if

$$
z_{0}^{i}=\left|z_{0}^{i}\right|=1 \text { for any } i \text {, such that } k_{1} \neq 0 \text { and } z_{0}^{m}=1 \text {. }
$$

The realization of both of these conditions simultaneously is possible only if the conditions of the Lemma are satisfied. In this case, obviously,

$$
\mathrm{z}_{0}^{\mathrm{r}}=1 \text {. }
$$

Otherwise, if the conditions of the Lemma are satisfied then for any root $z_{0}$ of the equation $z^{r}-1=0$ we obtain

$$
\mathrm{k}\left(\mathrm{z}_{0}\right)=1=\mathrm{z}_{0}^{\mathrm{m}},
$$

which implies that the root $\mathrm{z}_{0}$ is a root of the equation $\mathrm{k}(\mathrm{z})-\mathrm{z}^{\mathrm{m}}=0$. The Lemma is proved.

Now we return to the proof of the theorem.

A. First we suppose that the number $r$, appearing in the Lemma, is 1 . Then the function $z^{m}-k(z)$ has only 1 root on the unit circle. This root is equal to 1 and is simple, since $\mathrm{k}^{\prime}(1)=\mathrm{m}$. We will prove that in this case $\mathrm{z}^{\mathrm{m}}-\mathrm{k}(\mathrm{z})$ has exactly $\mathrm{m}-1$ roots inside $\Gamma: \mid$ $\mathrm{z} \mid=1$. Consider an auxiliary function

$$
f(z)=\frac{1-z^{-m} k(z)}{1-z^{-1}}
$$


Clearly, $f(z) \neq 0$ for all $z,|z|=1$ since the numerator of $f(z)$ may be zero only if $z=1$, but $f(1)=m-k^{\prime}(1) \geq 0$. Suppose now that $\operatorname{Ind}_{r} f(z)$ denotes the difference between the number of the roots and the number of the poles of the function $f(z)$ inside $\Gamma$.

By the principle of the argument:

$$
\operatorname{Ind}_{r} f(z)=\frac{1}{2 \pi} \Delta_{r} \operatorname{Arg} f(z)=\operatorname{Ind}_{r}\left[1-z^{-m} k(z)\right]-\operatorname{Ind}_{r}\left(1-z^{-1}\right)
$$

where $\Delta_{\mathrm{r}} \operatorname{Arg} \mathrm{f}(\mathrm{z})$ is the increment of the argument of $\mathrm{f}(\mathrm{z})$ when the argument $\Phi$ of $\mathrm{z}=\mathrm{e}^{\mathrm{i} \Phi}$ increases from 0 to $2 \pi$.

Let us consider the right side of (4.1). Since $\operatorname{Arg} f(1)=0$, it is easy to notice that

$$
\lim _{\Phi \rightarrow \pm 0} \operatorname{Arg}\left[1-\mathrm{e}^{-\mathrm{im} \Phi} \mathrm{k}\left(\mathrm{e}^{\mathrm{i} \Phi}\right)\right]=\lim _{\Phi \rightarrow \pm 0}\left[1-\mathrm{e}^{-\mathrm{i} \Phi}\right]= \pm \frac{\pi}{2} \text {. }
$$

At the same time if

$$
\begin{aligned}
& \Phi \in(0,2 \pi),\left|e^{-i m \Phi} k\left(e^{i \Phi}\right)\right|<1 \text { and, hence, } \\
& \operatorname{Arg}\left[1-e^{-i m \Phi_{k}}\left(e^{i \Phi}\right)\right] \in\left(-\frac{\pi}{2}, \frac{\pi}{2}\right)
\end{aligned}
$$

It follows that

$$
\operatorname{Ind}_{\mathrm{r}}\left[1-\mathrm{z}^{-\mathrm{m}} \mathrm{k}(\mathrm{z})\right]=-\frac{1}{2}=\operatorname{Ind}_{\mathrm{r}}\left[1-\mathrm{z}^{-1}\right]
$$

and, therefore,

$$
\operatorname{Ind}_{\mathrm{r}} \mathrm{f}(\mathrm{z})=0
$$

From the fact that

$$
f(z)=\frac{z^{m}-k(z)}{z^{m-1}(z-1)}
$$

has exactly $m-1$ poles inside $\Gamma$, we conclude that the number of roots of $f(z)$ inside $\Gamma$ is also $\mathrm{m}-1$.

Thus, the total number of roots (together with $\mathrm{z}=1$ ) of the function $\mathrm{z}^{\mathrm{m}}-\mathrm{k}(\mathrm{z})$ is the unit disc $|z| \leq 1$ is equal to $m$.

Now let us consider the general case $r>1$. We introduce the function

$$
F(z)=z^{\frac{m}{r}}-\sum_{i=0}^{\infty} k_{i} z^{\frac{r}{i}}
$$

By the definition of $\mathrm{r}$ it follows that all exponents of $\mathrm{z}$ in (4.2) are integers. Applying the previous reasonings to (4.2) we obtain that $\mathrm{f}(\mathrm{z})$ has exactly 


$$
\frac{\mathrm{m}}{\mathrm{r}}-1 \text { roots in the region }|\mathrm{z}|<1 \text { and one } \operatorname{root} \mathrm{z}=1 \text { on the boundary. }
$$

The set of all $r$-th roots of the roots of $F(z)$ gives us all roots of $z^{m}-k(z)$. On the other hand, it is obvious, that any root of $z^{\mathrm{m}}-\mathrm{k}(\mathrm{z})$ raised to the $\mathrm{r}$-th power is a root of $\mathrm{F}(\mathrm{z})$. Therefore, the set of all roots of $z^{m}-k(z)$ is described completely. The number of them is $\mathrm{m} ; \mathrm{m}-\mathrm{r}$ are inside the region $|\mathrm{z}| \leq 1$, and $\mathrm{r}$ roots are on the boundary.

Suppose now that $\mathrm{z}_{0}$ is a root of $\mathrm{z}^{\mathrm{m}}-\mathrm{k}(\mathrm{z})$ such that $\left|\mathrm{z}_{0}\right|=1$. Then:

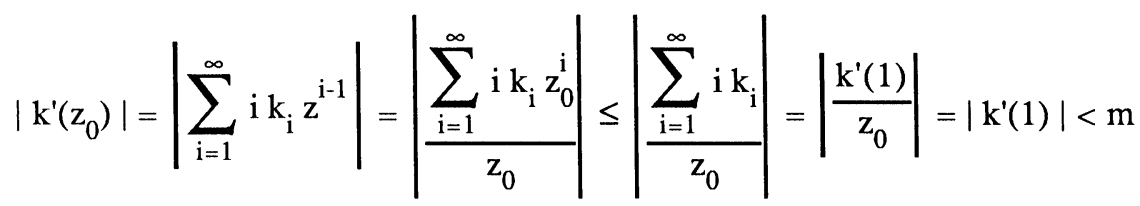

It follows that $\mathrm{k}^{\prime}\left(\mathrm{z}_{0}\right) \neq \mathrm{mz}^{\mathrm{m}-1}$, which implies that all roots on the boundary are simple. Part A of the theorem is proved.

Next we shall prove the part B. Since $\mathrm{k}^{\prime}(1)>\mathrm{m}$, there exists $\sigma>0$ such that $\mathrm{k}(\rho)<\rho^{\mathrm{m}}$ for any $\rho \in[1-\delta, 1]$. Therefore, the inequality $|\mathrm{k}(\mathrm{z})|<\left|\mathrm{z}^{\mathrm{m}}\right|$ is correct for any $z$, such that $|z|=\rho$. Using the theorem of Rouche, we obtain that $z^{m}-k(z)$ has exactly $\mathrm{m}$ roots in the region $|\mathrm{z}|<1$. The number of roots on the boundary, as before, depends on the value of $r$. If $r>1$ then, by the lemma, there are $r$ roots on the boundary which represent a group of $\mathrm{r}$-th roots of 1 . The simplicity of these roots is proved as before.

\section{REFERENCES}

[1] Abolnikov, L.M. Investigation of a Class of Discrete Markov Processes. Izv. ANSSR, Tekhnicheskaya Kibernetika, N2:69-82 (1977). (English translation: Engineering Cybernetics, 15(1977)N2:51-63).

[2] Abolnikov, L.M., Dshalalow, E. A. Feedback Queueing Systems: Duality Principle and Optimization. Automation and Remote Control 39:11-20 (1978).

[3] Abolnikov, L. M. A Single Level Control in Moran's Problem with Feedback. Operations Research Letters 2, N1:16-19 (1983).

[4] Bahary, E., Kolesar, P. Multilevel Bulk Service Queues. Oper. Res. 20:407-420 (1972).

[5] Bailey, N. T. On Queueing Process with Bulk Service. J. Roy. Statist. Soc. B. $16: 80-87$ (1954).

[6] Delbrouek, L. A Feedback Queueing System with Batch Arrivals, Bulk Service, and Queue-Dependent Service Time. J. Assoc. Comput. Mach. 17:314-323 (1970).

[7] Harris, C. M., Marlin, P. E. A note on Feedback Queues with Bulk Service. J. Assoc. Comput. Mach. 19:727-733 (1972). 
[8] Kopocinska, I. GI/M/I Queueing Systems with Service Rates Depending on the Length of Queue. Zastosow. Matem. 11:265-279 (1970).

[9] Loris-Teghem, J. Condition Necessaire d'Ergodisme pour un Processus Stochastique lie a un Systeme d'Attente a Arrivees et Services en Groupes d'Effectif Aleatore. Bull. Cl. Sci. Acad. Roy. Belg. 52:382-389 (1966).

[10] Moustafa, M.D. Input-Output Markov Processes. Proc. Koninkijke Nederlande Akad. Wetenschappen 60:112-118 (1957).

[11] Neuts, M. F. Queues Solvable without Rouche's Theorem. Operat. Res. 27(4):767-781 (1979). 


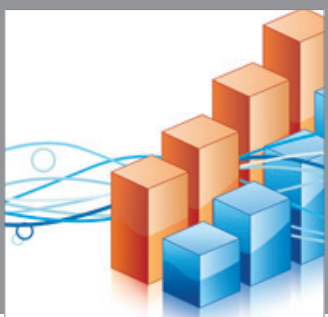

Advances in

Operations Research

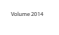

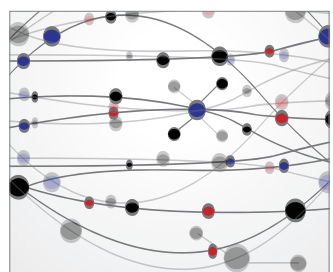

\section{The Scientific} World Journal
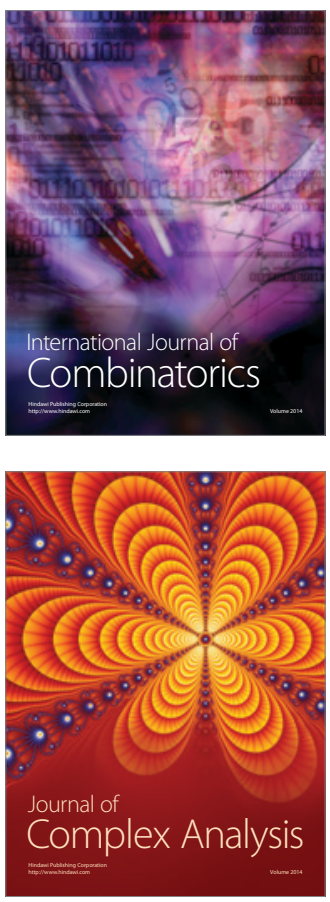

International Journal of

Mathematics and

Mathematical

Sciences
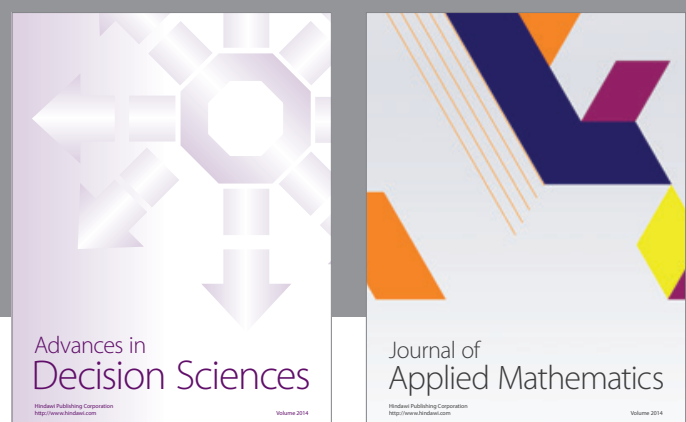

Journal of

Applied Mathematics
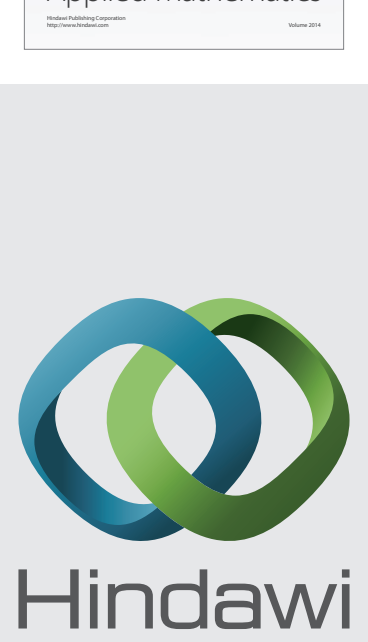

Submit your manuscripts at http://www.hindawi.com
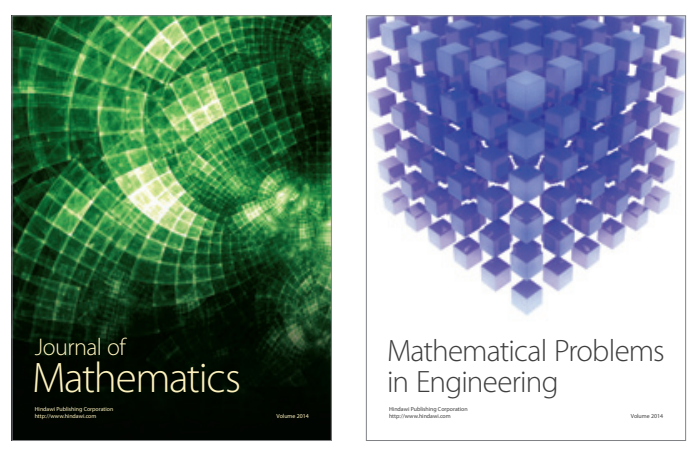

Mathematical Problems in Engineering
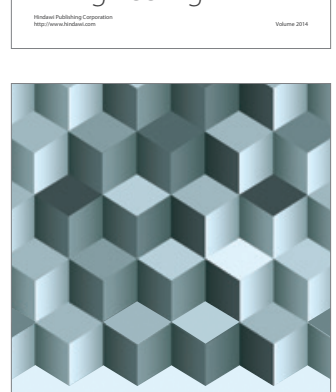

Journal of

Function Spaces
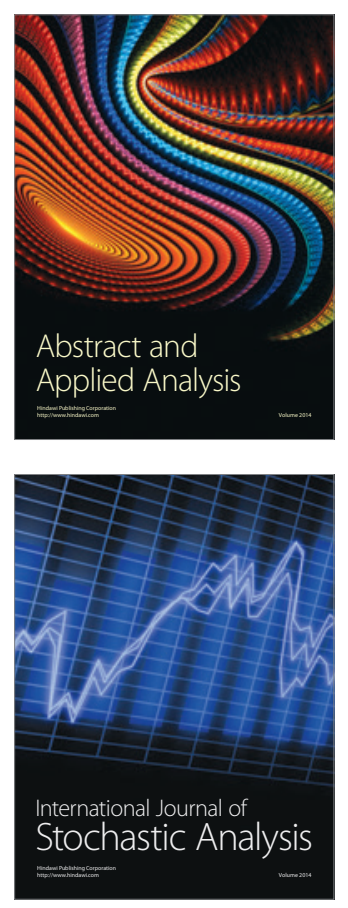

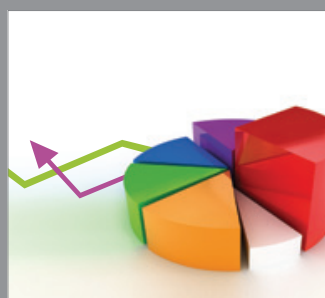

ournal of

Probability and Statistics

Promensencen
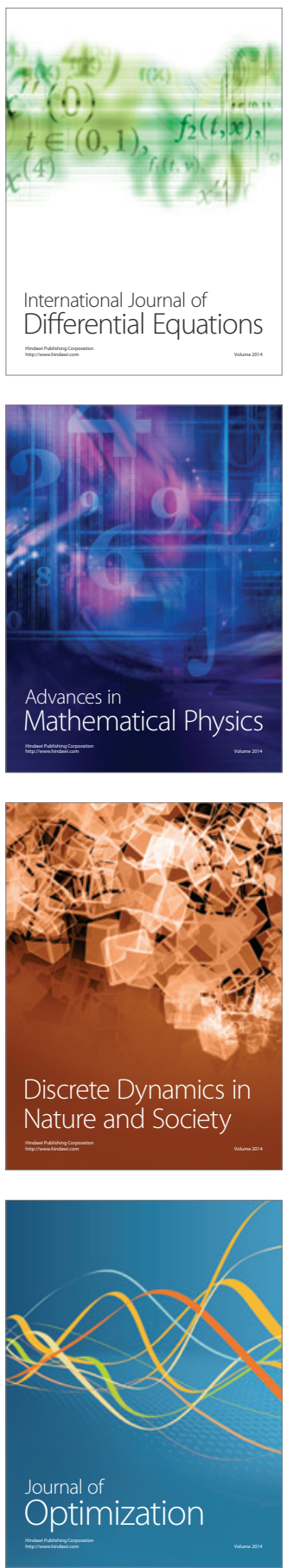